Research Article

\title{
Identification and Evolution of the Noncoordination Coupling Relationship between Tourism Poverty Alleviation and Ecological Environments in Poor Mountainous Areas
}

\author{
Qu Qin $\mathbb{D}^{1},{ }^{1}$ Zeli Hu, ${ }^{1}$ Anle Liu, ${ }^{1}$ Yan Huang, ${ }^{1}$ and Fengtai Zhang $\mathbb{D}^{2}$ \\ ${ }^{1}$ School of Tourism and Historical Culture, Liupanshui Normal University, Liupanshui, Guizhou 553004, China \\ ${ }^{2}$ School of Management, Chongqing University of Technology, Chongqing 400054, China \\ Correspondence should be addressed to Qu Qin; Qinqu2008@126.com
}

Received 30 April 2020; Accepted 17 June 2020; Published 1 August 2020

Academic Editor: Maria Alessandra Ragusa

Copyright $(2020$ Qu Qin et al. This is an open access article distributed under the Creative Commons Attribution License, which permits unrestricted use, distribution, and reproduction in any medium, provided the original work is properly cited.

Tourism poverty alleviation and ecological environments are closely associated with each other's dissipation structure, which contains various coordinated and noncoordinated coupling states. Based on the perspective of reverse thinking and problem diagnosis, this paper constructs a bridge from uncoordinated pathology to coordinated development. From the perspective of incongruity, the framework model and evaluation index system of tourism poverty alleviation and ecological environments incongruity coupling coordination driving mechanism are constructed. Also, the variation coefficient method is used to calculate the weight of each evaluation index and the coupling relationship and evolution of tourism poverty alleviation and ecological environments in Liupanshui city are analyzed by the noncoordination coupling function. The results suggest the following: (1) During the study period, the poverty alleviation level of tourism in Liupanshui city presents a continuous growth curve. Meanwhile, ecological environment development level depicts rapid growth initially and then slows down and improves further. In this way, it shows different stage characteristics from the tourism poverty alleviation level. (2) The discordant coupling between tourism poverty alleviation and ecological environments in Liupanshui city shows a decreasing curve. So, the noncoordinated development relationship between tourism poverty alleviation and ecological environments is significant.

\section{Introduction}

Poverty is a universal phenomenon in the world [1]. Antipoverty has always been an important issue faced by mankind since many years. In recent years, pro-poor Tourism (PPT) has become the main factor of poverty alleviation in China [2]. The concept of tourism poverty alleviation was put forward by the British International Development Agency in the 1990s, which states that tourism income should exceed overall costs or expenses incurred in order to extend benefits to the poor population $[3,4]$. Presently, poor population in China is mainly distributed in mountainous areas, which have a high geographical overlap with the spatial distribution of tourism resources [5]. The tourism poverty alleviation of those areas is closely related to the ecological environment. On the one hand, the poor mountainous areas are less affected by outside world and are highly rich in ecological tourism resources, which provide crucial resources for poverty alleviation through tourism. On the other hand, the ecological environment in poor mountainous areas is fragile. The process of tourism poverty alleviation would cause different kinds of damage to the ecological environment, such as disordered development of tourism resources, blind planning, unreasonable development of land resources, disordered distribution of construction facilities, reduction of biodiversity, and serious water pollution, which eventually lead to the series of ecological and environmental problems [6].

As a result, the sustainable development of tourism poverty alleviation (Sustainable Tourism for Eliminating 
Poverty, ST-EP) is gaining huge attention and recognition worldwide [7]. The core idea of sustainable development of tourism poverty alleviation is to consider and position tourism as a means of poverty reduction in order to solve social, cultural, and environmental problems [8]. In this context, it is said that tourism poverty alleviation in poor mountainous areas must be treated as a system requiring adequate allocation and optimum use of resources $[9,10]$. The phenomenon of sustainable tourism poverty alleviation should be carried out on the premise that participation of poor population in tourism is extremely necessary for poverty alleviation [11].

Incongruity refers to the inappropriate and discordant coordination between two or more things and also extends to the noncommon development of things, systems, and regions. There are several obvious "externalities" between things. The development of one thing is obtained by damaging the interests of "other things," thus hindering overall benefit of the system and optimization of sustainable development. It is the result of negative feedback, discrimination, and disclosure of the rationality that results from the perspective of reverse thinking and problem diagnosis [12]. Therefore, identification of tourism poverty alleviation and ecological environments in poor mountainous areas can be analyzed from the perspective of noncoordination, characteristics, effects, and evolution trends of the interaction between tourism poverty alleviation and ecological environment. This is the real problem of the relationship between people and land in the poor mountainous areas, which has certain inevitability.

In poor mountainous areas, the development of tourism poverty alleviation has changed the original local ecological environment. The essence of tourism poverty alleviation is a kind of interference to the local ecological environment, which has wider impact on ecological and cultural environments of the local system. The tourism poverty alleviation development affects original ecological environment significantly [13-15]. In recent years, many poor mountainous areas have developed into tourist destinations. On the one hand, poverty alleviation through tourism promotes social and economic development; on the other hand, the conflict between population, resources, environments, and development is intensified by predatory development [16]. Therefore, it is of great theoretical and practical significance to study the incongruent coupling between tourism poverty alleviation and ecological environment.

Existing research studies mainly focus on mathematical survival theory of the relationship between tourism and ecological environments [17], the dynamic model of tourism development and ecological environments [18-20], and the coupling relationship between tourism industry [21, 22], tourism economy [23-25], tourism traffic [26], ecological environments, and so forth. However, there are few research literatures on the coordination between tourism poverty alleviation and ecological environments, especially the research on the coordination between tourism poverty alleviation and ecological environments in poor mountainous areas. Based on it, this study takes Liupanshui city, Guizhou province, as an example to measure the level of poverty alleviation and the ecological environment development in poor mountainous areas and establishes a model to distinguish the uncoordinated relationship between tourism poverty alleviation and ecological environments in order to prevent the destruction of ecological environments in the process of tourism poverty alleviation, the reduction of quality of tourism resources, and forming a vicious circle $[27,28]$. Theoretically, the bridge from disharmony to harmony between tourism poverty alleviation and ecological environments should be constructed to promote the coordinated development of tourism poverty alleviation and ecological environments in poor mountainous area. The study provides a good reference basis and feasible path for the sustainable and healthy development of regional economy, society, and ecological environments.

\section{Overview of the Study Area}

Liupanshui city is located in the western part of Guizhou province, which belongs to the Wumeng mountain destitute concentration area, and stands on the slope of the first-grade and second-grade platform in the eastern part of YunnanGuizhou province between $25^{\circ} 19^{\prime} 44^{\prime \prime} \mathrm{N}-26^{\circ} 55^{\prime} 33^{\prime \prime} \mathrm{N}$ $104^{\circ} 18^{\prime} 20^{\prime \prime} \mathrm{E}-105^{\circ} 42^{\prime} 50^{\prime \prime} \mathrm{E}$ [29] (Figure 1). The city borders Anshun city, Qiannan Buyei and Miao autonomous prefecture, Bijie city, and Qujing city that belong to Yunnan province. The total land area is $9926 \mathrm{~km}^{2}$, accounting for $5.63 \%$ of the total area of Guizhou province. The territory is rich in mineral resources, such as coal and iron, and therefore is known as Jiangnan coal capital possessing 30 types of mineral resources.

The total population of the city is 3.34 million, $77 \%$ of which is agricultural population, located in scattered form in mountain areas. There are four counties (districts); three of them are national-level poverty-stricken counties, one is provincial-level poverty-stricken county, and remaining $60 \%$ are villages for poverty alleviation and development [30]. In 2017, there were 186,700 poor people in the city, with a poverty rate of $7.34 \%$. Tourism poverty alleviation has become one of the main methods to get rid of poverty. At present, the city has a total of 42 natural scenery investment tourism enterprises, and the establishment of 205 tourism villages for poverty alleviation is worth appreciating. The number of tourists the city received increased from 4.4438 million in 2010 to 22.4641 million in 2017, with an average annual growth of $57.93 \%$. The tourism revenue increased from 3.091 billion Yuan to 17.683 billion Yuan, with an average annual increase of 67.47 percent. In recent years, the income of 123,700 poor people has been increased through tourism. Karst landforms are quite significant, mountains valleys are deep, cultivated lands are piecemeal, and ecological environments are fragile. Rocky desertification accounts for $26 \%$ of land areas, 4.6346 million mu are arable lands, sloping lands above $25^{\circ}$ account for $47 \%$, the water loss and soil erosion area is $52 \%$ of the total land area, and barren hills and slopes cover 273,900 mu. Regional forest coverage rate is low and natural woodland decreases, but artificial secondary forest increases. The forest coverage rate in mountainous areas has dropped to $7.55 \%$ but reached 


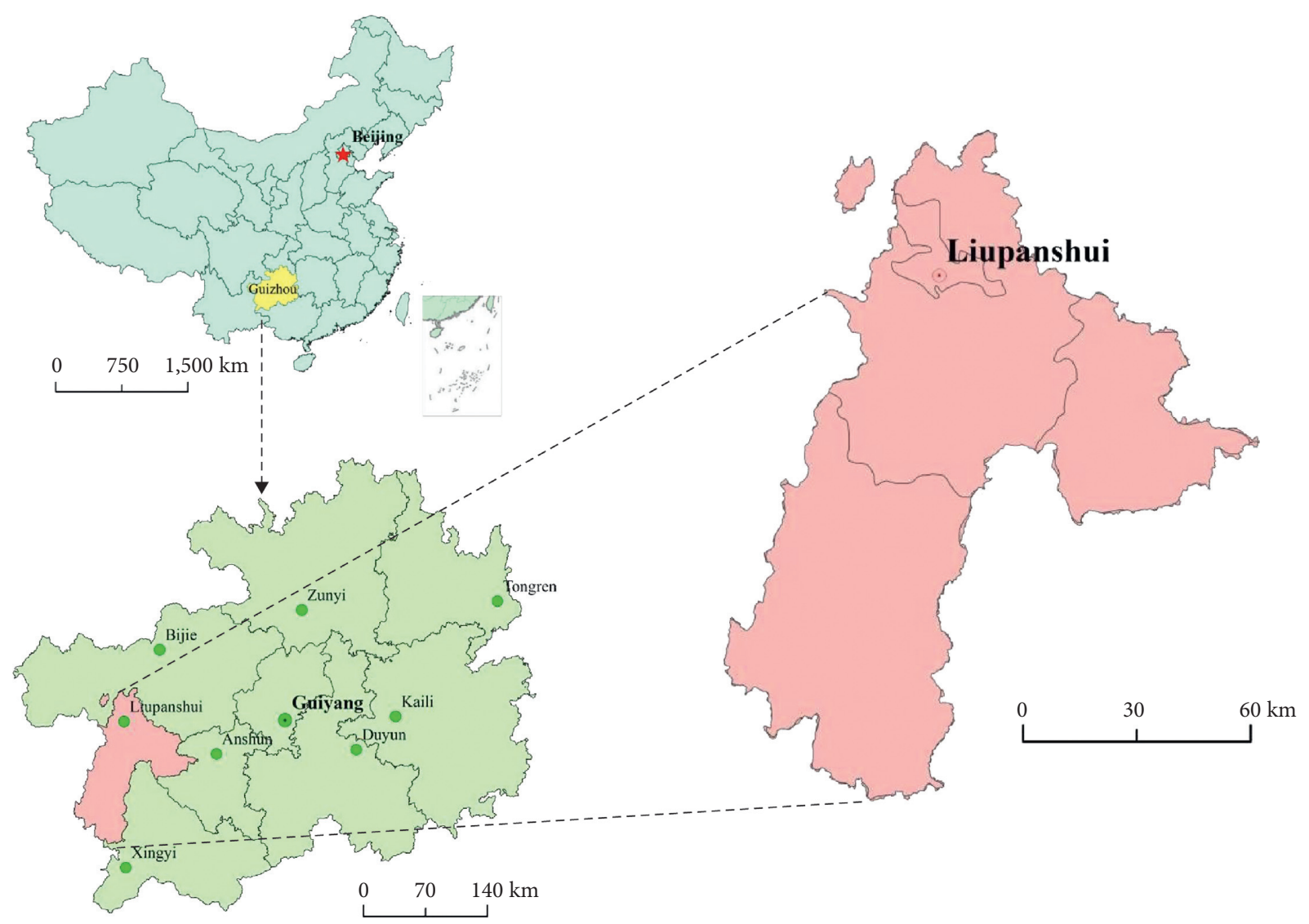

Figure 1: The location of the study area.

$59.33 \%$ in 2017 after years of efforts, most of which is secondary vegetation [31].

\section{Research Methods}

\subsection{Evaluation Framework Model Constructions and Evaluation Index Analyses}

3.1.1. Evaluation Framework Model Constructions. This study evaluates the level of tourism poverty alleviation and the ecological environment development and distinguishes the incongruent coupling between them. Therefore, it is necessary to construct the incongruent coupling evaluation framework model of tourism poverty alleviation and ecological environments [32]. Tourism poverty alleviation and ecological environments are two distinct systems with complex structure and extensive contents. There is a strong interaction coupling between the two systems. On the one hand, the optimization of the carrier of tourism poverty alleviation resources can promote the construction of ecological environments. The development and protection of tourism resources are required not only for ecological environment protections but also for the construction of ecological civilization. Tourism activities derive from the beautiful environment and eventually go back to the environment. We develop and plan tourism resources based on the ecological concept and idea of low carbon, the unity of human and nature, and the ideology of sustainable development in order to create and develop high-quality tourist attractions. This helps in protecting the ecological environment through ensuring optimum utilization and allocation of resources. On the other hand, ecological environment protection provides necessary basic conditions for the development of tourism. Tourism industry is strongly dependent on enriching and nurturing ecological environment. Therefore, protection of original ecological environment and the restoration of the damaged ecological environment are necessary as they could greatly improve and enhance the quality of tourism resources. At the same time, beautiful natural environment can attract more tourists, upgrade tourism competitiveness, and expand tourism market demands and promotes overall development of tourism [33].

In the process of tourism poverty alleviation, there is high need of investment of several resources. The concept of tourism poverty alleviation can be put into effect or reality through sourcing and allocating necessary tourism resources. The overall improvement of ecological environment requires optimum use of tourism resources, and then the development of tourism resources is actualized, resulting in pressures on the ecological environment. For protecting ecological environment, it is necessary to implement ecological environment protections and increase investment for improving overall efficiency of ecological environment protections. It helps in providing right direction to the ecological environment, creating and nurturing conducive 
ecological environment conditions, and providing excellent tourism resources for tourism poverty alleviation. All these aspects would facilitate the implementation of tourism poverty alleviation theorem in a good and right direction, enabling tourism poverty alleviation and ecological environments complementing each other and establishing a coupling pattern of virtuous cycle development (as shown in Figure 2).

3.1.2. Analyses of Evaluation Indicators. According to the above evaluation framework model and inferences of previous research results [34-36], on the basis of principles of scientificity, systematic framework, independence, feasibility, and representativeness, in combination with the study of actual situation of poverty-stricken mountainous areas, the coupling evaluation index system of tourism poverty alleviation and ecological environments is established. It is found that tourism poverty alleviation system is composed of the tourism poverty alleviation pressure, the tourism poverty alleviation input, and the tourism poverty alleviation effect (as shown in Table 1). Among them, the poverty alleviation pressure index is composed of three factors: size of poor population, incidence of poverty, and population density. The index of tourism poverty alleviation input includes five elements: the number of scenic spots, fixed asset investment, restaurant spaces, resort real estate, and accommodation beds. The indicator of poverty alleviation includes seven factors: tourist arrivals, fiscal revenue, total social income, tourism revenue, per capita GDP, per capita net income of farmers, and the number of people lifted out of poverty through tourism. The eco-environment system consists of eco-environment pressure, eco-environment protection input, and eco-environment protection efficiency (as shown in Table 2). Among them, the environment pressure index includes five elements: domestic garbage cleaning and transportation volume, discharge of domestic sewage, discharge of domestic waste gas, intensity of pesticide applications, and intensity of chemical fertilizer applications. The investment index of ecological and environmental protections includes afforestation area, environmental protection investment index, sewage treatment capacity, and garbage collection facilities. The efficiency index of ecological environment protections includes six factors: the rate of meeting the standard of drinking water quality, per capita public green space areas, the rate of days with good air quality, the rate of domestic sewage treatments, the rate of domestic garbage treatments, and the vegetation coverage rate.

\subsection{Establishment of Evaluation Models}

3.2.1. Determining the Weight of Evaluation Indicators. In order to avoid the inconsistencies between the measurement results and the objective reality due to the determination of weights by subjective factors, this study uses the variation coefficient method to calculate the weight values of each index, and the results are relatively objective $[37,38]$. The specific steps are as follows:
(1) Calculate the mean value of the characteristic values of each evaluation index:

$$
\bar{x}_{j}=\frac{1}{n} \sum_{i=1}^{n} x_{i j}, \quad(i=1,2, \ldots, n ; j=1,2, \ldots, m) .
$$

In the formula, $\bar{x}_{j}$ is the average value of the characteristic value of the item $j$ of all evaluation objects, and $x_{i j}$ is the characteristic value of the evaluation object $i$ and the evaluation index $j$.

(2) Calculate the standard deviation of the characteristic values of each evaluation index:

$$
S_{j}=\sqrt{\frac{1}{n} \sum_{i=1}^{n}\left(x_{i j}-\bar{x}_{j}\right)} .
$$

In the formula, $S_{j}$ is the standard deviation of the characteristic value of the $J^{\text {th }}$ evaluation index.

(3) Calculate the variation coefficient of the characteristic values of each evaluation index:

$$
V_{j}=\frac{S_{j}}{\bar{x}_{j}} \text {. }
$$

In the formula, $V_{j}$ is the variation coefficient of the evaluation index $j$.

(4) Calculate the weight of each evaluation index:

$$
W_{j}=\frac{V_{j}}{\sum_{j=1}^{m} V_{j}} .
$$

In the formula, $W_{j}$ is the weight value of each evaluation index $j$.

\subsubsection{Establishing the Discrimination Function of Incon-} gruent Coupling Relationship

(1) Standardization of Original Data. The judgment matrix is composed of $n$ evaluation objects and $m$ indicators:

$$
R=\left(x_{i j}\right)(a=1,2, L, n ; b=1,2, L, m) .
$$

If the index is a positive index, that is, the larger the value, the better, there will be

$$
r_{i j}=\frac{\left[X_{i j}-\min \left(X_{i j}\right)\right]}{\max \left(X_{i j}\right)-\min \left(X_{i j}\right)} .
$$

If the index is a negative index, that is, when the value is smaller, the better, there will be

$$
r_{i j}=\frac{\left[\max \left(X_{i j}\right)-X_{i j}\right]}{\max \left(X_{i j}\right)-\min \left(X_{i j}\right)} .
$$

In the formula, $X_{i j}$ is the $j^{\text {th }}$ evaluation index value of the $i^{\text {th }}$ evaluation object, and $\max \left(X_{i j}\right)$ is the maximum value of 


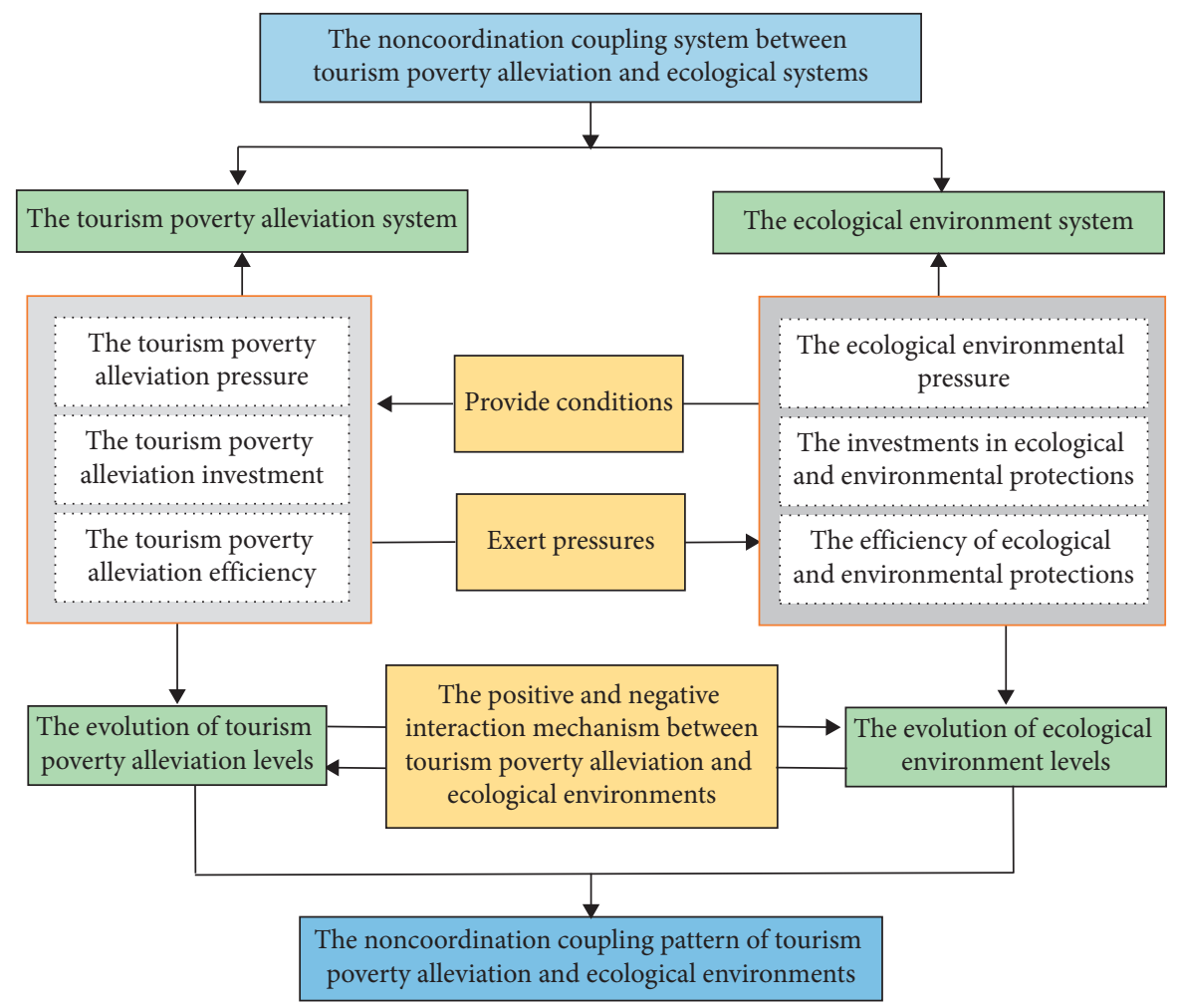

Figure 2: The coupling noncoordination drive mechanism assessment model framework of the tourism poverty alleviation and ecological environments.

the $i^{\text {th }}$ evaluation object. $\max \left(X_{i j}\right)$ is the minimum value of the $i^{\text {th }}$ evaluation object.

(2) Distinguish the Uncoordinated Coupling Relationship between Tourism Poverty Alleviation and Ecological Environment. Under the pressure of tourism poverty alleviation, tourism poverty alleviation input is an institutional arrangement based on the status quo and development requirements and has an impact on the ecological environment. Its noncoordination is the feedback mechanism of the effect of institutional arrangement, as well as the external expression of whether the development strategy and concept of tourism poverty alleviation scenic spots are sustainable and coordinated. Its time and space are a dynamic expression process.

Therefore, "incongruity" is the spatial and temporal function of sustainable development. Analyzing from the perspective of time, the development of a scenic spot is to constantly restrain the incompatibility of tourism space expansion, ensuring that development of the scenic spot took place in a spiral growth process. Analyzing from the perspective of space, due to the different location conditions, natural conditions, cultural conditions, historical bases, government policies, etc., different scenic spots led to the noncoordinated spatial pattern of tourism poverty alleviation investment. For example, some scenic spot poverty alleviation investments show a leading trend; its development has a great impact on the ecological environment; some scenic spot tourism poverty alleviation investments are relatively balanced and coordinated with the development of ecological environments. Lastly, some scenic spot poverty alleviation investments lag behind and have little impact on the ecological environment. Therefore, it is believed that incongruity is the "reverse mapping" of sustainable development; that is, the high level of incongruity indicates the low level of sustainability, while the low level of incongruity suggests the high level of sustainability; they inverse each other [39].

Based on the above analysis, this study believes that tourism poverty alleviation and ecological environments have an interactive coupling spatial-temporal function. On the one hand, tourism poverty alleviation exerts a threatening effect on the ecological environment through tourism resource development, traffic expansion, economic growth, and population poverty alleviation. It is also possible to reduce the "disturbance" to the environment due to the aggregation of population, tourism industry, and tourism capital in tourist attractions. On the other hand, the ecological environment can restrict the tourism poverty alleviation through the livability, uniqueness, and reputation of the environment. Different coupling states are shown in different regions and time periods. Some coupling states are coordinated or uncoordinated. On the basis of the interactive correlation between coordination and noncoordination, the noncoordination coupling discrimination model is established [32]. The specific formula is as follows: 
TABLE 1: The pro-poor tourism system assessment indexes and meanings in poor mountainous areas.

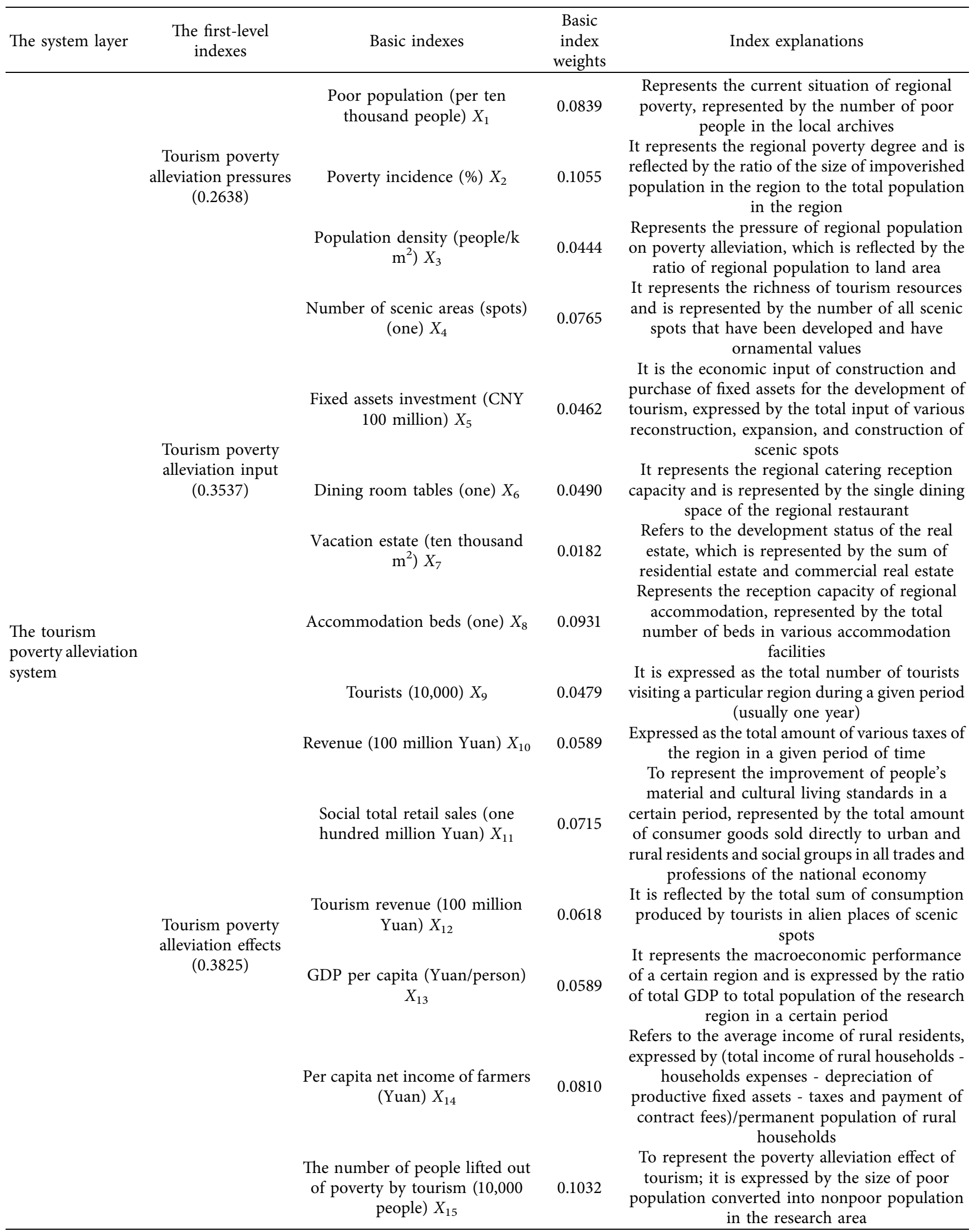


TABLE 2: The eco-environment system assessment indexes and meanings in poor mountainous areas.

\begin{tabular}{ccc} 
The system layer The first-level indicators $\quad$ Basic indicators & $\begin{array}{c}\text { Weights of } \\
\text { basic } \\
\text { indicators }\end{array}$ \\
\hline
\end{tabular}

Domestic garbage removal volume (10,000 tons) $Y_{1}$

Discharge of domestic sewage (10000 tons) $Y_{2}$

The ecological environment pressure $(0.2852)$

Domestic gas emissions (ten thousand standard cubic) $Y_{3}$

Intensity of pesticide application $\left(\mathrm{kg} / \mathrm{hm}^{2}\right) Y_{4}$

Intensity of fertilizer application $\left(\mathrm{kg} / \mathrm{hm}^{2}\right) Y_{5}$

Afforestation area $\left(\mathrm{hm}^{2}\right) Y_{6}$

The ecoenvironment system

0.0694

0.1015

0.0139

0.0285

0.0719
Investment in ecological environment protection (0.2339)

Ecological environment protection efficiency (0.4809)

\section{Environmental investment} index (\%) $Y_{7}$

Sewage treatment capacity (t/day) $Y_{8}$

Rubbish collection facilities (one) $Y_{9}$

Compliance rate of drinking water quality (\%) $Y_{10}$

Per capita public green areas

$$
\left(m_{2}\right) Y_{11}
$$

0.0663

The rate of days with good air quality (\%) $Y_{12}$

Domestic sewage treatment rate $(\%) Y_{13}$

Domestic waste disposal rate (\%) $Y_{14}$

Vegetation coverage rate (\%) $Y_{15}$

0.0156

0.0422

0.0771

0.0781
Represents the pressure of domestic garbage on the ecological environment, represented by the amount of domestic garbage that can be transported to the waste consumption site or transfer site

Represents the pressure of domestic sewage on the water environment

It is reflected by the amount of sewage discharged by local residents

It represents the pressure generated by residents' living exhaust gas to the atmospheric environment and is reflected by the amount of exhaust gas emitted by local residents

It represents the pressure of sightseeing agricultural production on the ecological environment and is reflected by the amount of pesticide applied per hectare per year

It represents the pressure of sightseeing agricultural production on the ecological environment and is reflected by the amount of fertilizer applied per hectare per year

Representing the afforestation status of barren mountains and wastelands, represented by the sum of plantation area on barren mountains and wastelands and afforestation area sown by aircrafts

It represents the adequacy of regional environmental management investments and is reflected by the ratio of regional environmental protection investment to GDP Refers to the daily average quantity of sewage treatment, expressed by tons of sewage treatment per day It is represented by the total number of garbage cans, garbage compression truck, garbage transfer station, etc.

Characterization of regional water quality status. Reflected by the ratio of water bodies above grade II to the total water body according to the drinking water sanitary standard (GB5749)

It represents the quality of living environments and life of regional residents, which is reflected by the ratio of the area of regional green space to the total local population Represents the air quality in the region. It is reflected by
the ratio of days with good air quality to the total number of days in a year

Characterization of regional sewage treatment status. It is reflected by the ratio of sewage treatment volume to sewage discharge quantity in an area

Represents the status of regional garbage disposal. It is reflected by the ratio of the treated domestic garbage to the total domestic garbage

Represents the overall greenbelt status of the region. It is reflected by the ratio of vegetation area to total land area

$$
\begin{aligned}
N D & =1-D, \\
D & =(C \times T)^{1 / 2}, \\
C & =\left\{\frac{\left(U_{1} \times U_{2}\right)}{\left(U_{1}+U_{2}\right)^{2}}\right\}^{1 / 2}, \\
T & =a \times U_{1}+b \times U_{2} .
\end{aligned}
$$

In the formula, $N D$ is the noncoordination coupling degree, $D$ is the coordination coupling degree, $C$ is the coupling degree, $T$ is the comprehensive level of tourism poverty alleviation and ecological environments, $U_{1}$ is the comprehensive development level of tourism poverty alleviation, $U_{2}$ is the comprehensive development level of ecological environments, $a$ and $b$ are the contribution rates of tourism poverty alleviation and ecological environments to the system, respectively, and $a+b=1$; besides tourism 
poverty alleviation and ecological protection are equally important, so $a=b=0.5$.

Based on the reference of existing literature research results [40-42], the discordant coupling degree between tourism poverty alleviation and ecological environments is divided into the following four stages: (1) $0<N D \leq 0.2$, lowlevel uncoordinated coupling: tourism poverty alleviation and ecological environments tend to have benign interaction; (2) $0.2<N D \leq 0.5$, antagonistic uncoordinated coupling: people realize the importance of ecological environment protections; therefore environmental investment is increased and nonbenign interaction relationship between tourism poverty alleviation and ecological environments is improved; (3) $0.5<N D \leq 0.8$, running-in uncoordinated coupling: the intimidated effect of tourism poverty alleviation to ecological environments is gradually strengthened, the ecological environment is deteriorated, and the nonbenign interaction between tourism poverty alleviation and ecological environments is obvious; (4) $0.8<N D \leq 1$, high-level uncoordinated coupling: tourism poverty alleviation and ecological environments are in the state of uncoordinated development.

\section{Results}

4.1. Data Sources and Calculations. The relevant data are mainly from the statistical yearbook of Liupanshui city (2004-2018), and the statistical results are released by Liupanshui poverty alleviation development bureau and Liupanshui culture, radio, video, and tourism bureau, the communique from social and economic development of Liupanshui city (2004-2018), the communique from the water resource of Liupanshui city (2004-2018), the field survey of 2017, relevant literature data, and so forth.

Relevant data are substituted into equations (6)-(11) to calculate the inharmonious coupling between tourism poverty alleviation and ecological environments in Liupanshui city. The results are shown in Table 3. Among them, the evolution process of tourism poverty alleviation level is shown in Figure 3, the evolution process of ecological environment level is shown in Figure 4, and the evolution process of the incongruent coupling between tourism poverty alleviation and ecological environments is shown in Figure 5.

\subsection{Analyses of Tourism Poverty Alleviation and the Ecological Environment Development Level in Liupanshui City}

4.2.1. Analyses of Poverty Alleviation Development Level of Tourism in Liupanshui City. From the comprehensive score in Table 3 and the evolution process in Figure 3, it can be found that, during the study period, the poverty alleviation level of tourism in Liupanshui shows a continuous growth curve, rising from 0.2198 in 2003 to 0.7963 in 2017, with an increase rate of $262.28 \%$. Although tourism poverty alleviation development level has been rising during this period, the rising velocity is not the same in each time period: from 2003 to 2007, the development level of tourism poverty alleviation is in the slowly rising stage; from 2008 to 2011, it
TABLE 3: The noncoordination coupling evaluation results between pro-poor tourism and eco-environment in Liupanshui city.

\begin{tabular}{cccccc}
\hline Time & $U_{1}$ & $U_{2}$ & $C$ & $T$ & $N D$ \\
\hline 2003 & 0.2198 & 0.1726 & 0.2464 & 0.1962 & 0.6879 \\
2004 & 0.2247 & 0.2022 & 0.2493 & 0.2134 & 0.6736 \\
2005 & 0.2240 & 0.2432 & 0.2450 & 0.2239 & 0.6654 \\
2006 & 0.2221 & 0.3034 & 0.2440 & 0.2627 & 0.6398 \\
2007 & 0.2241 & 0.3475 & 0.2383 & 0.2858 & 0.6265 \\
2008 & 0.2483 & 0.4329 & 0.2316 & 0.3406 & 0.5951 \\
2009 & 0.2966 & 0.4589 & 0.2384 & 0.3778 & 0.5705 \\
2010 & 0.2931 & 0.5007 & 0.2329 & 0.3969 & 0.5624 \\
2011 & 0.3281 & 0.5359 & 0.2355 & 0.4320 & 0.5421 \\
2012 & 0.3447 & 0.5409 & 0.2377 & 0.4428 & 0.5354 \\
2013 & 0.4477 & 0.5985 & 0.2448 & 0.5231 & 0.4913 \\
2014 & 0.5285 & 0.6220 & 0.2483 & 0.5753 & 0.4646 \\
2015 & 0.5971 & 0.6755 & 0.2491 & 0.6363 & 0.4365 \\
2016 & 0.6516 & 0.7271 & 0.2493 & 0.6894 & 0.4134 \\
2017 & 0.7963 & 0.7834 & 0.2499 & 0.7898 & 0.3716 \\
\hline
\end{tabular}

$U_{1}$ refers to the tourism poverty alleviation level; $U_{2}$ is the ecological environment level; $C$ is the coupling degree; $T$ is the comprehensive level of tourism poverty alleviation and ecological environments; $N D$ is the noncoordination coupling degree.

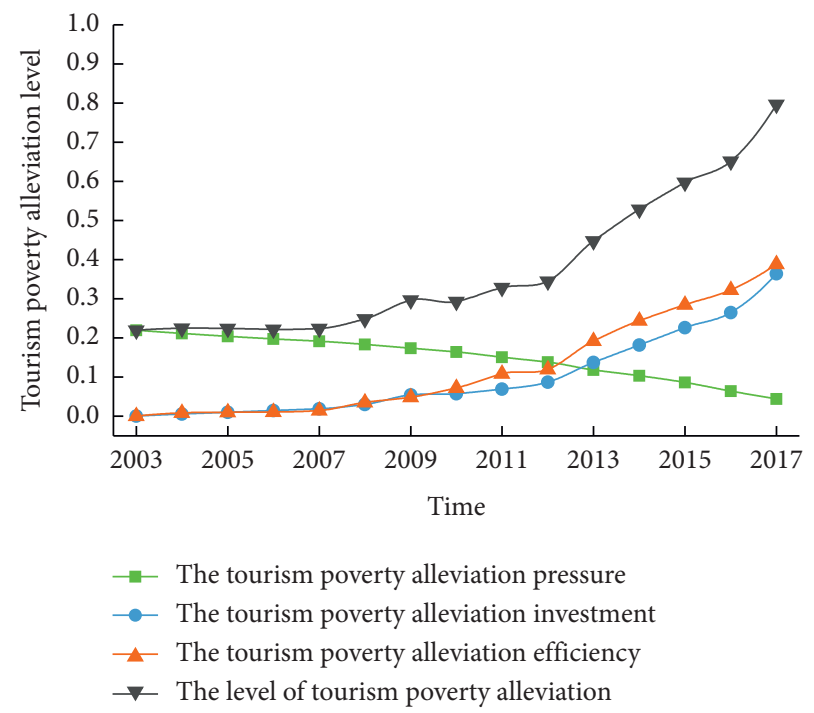

Figure 3: The evolution process of pro-poor tourism level in Liupanshui.

is in the quicker rising stage; and, from 2012 to 2017, it is in the rapidly rising development stage. This is related to the different tourism poverty alleviation policy and the varying application of tourism poverty alleviation work in each time period.

From the evolution process of each subsystem of tourism poverty alleviation, a continuous decline curve appears in the pressure of tourism poverty alleviation, from 0.2194 in 2003 to 0.0444 in 2017 , with a decline rate of $394.14 \%$. The input and efficiency of tourism poverty alleviation are on a rising trend from 0.0003 and 0.0001 in 2003 to 0.3637 and 0.3882 in 2017 , with increase rates of $121,133.33 \%$ and $388,100.00 \%$, respectively. This indicates that Liupanshui city tourism development level was extremely backward in 


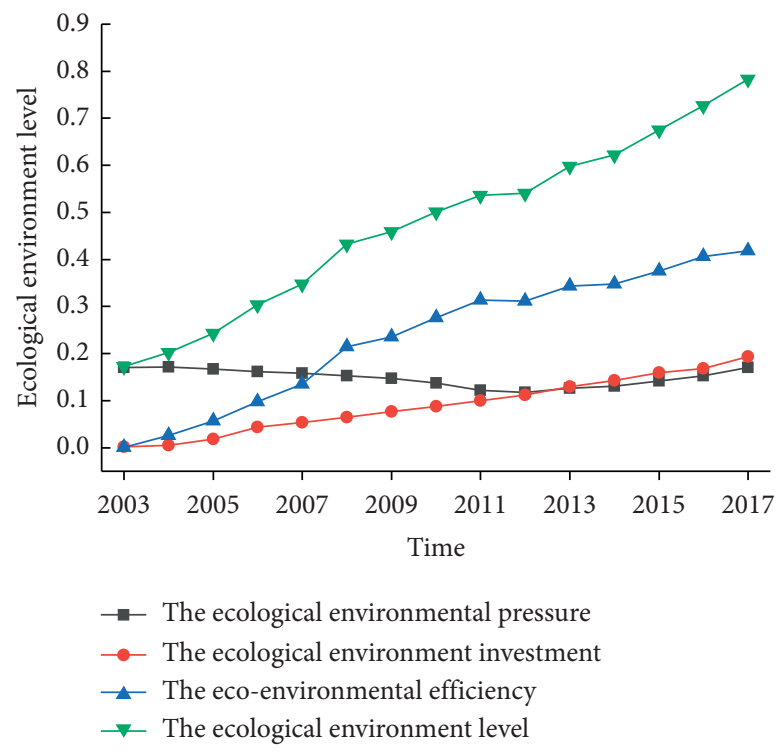

Figure 4: The evolution process of eco-environment level in Liupanshui city.

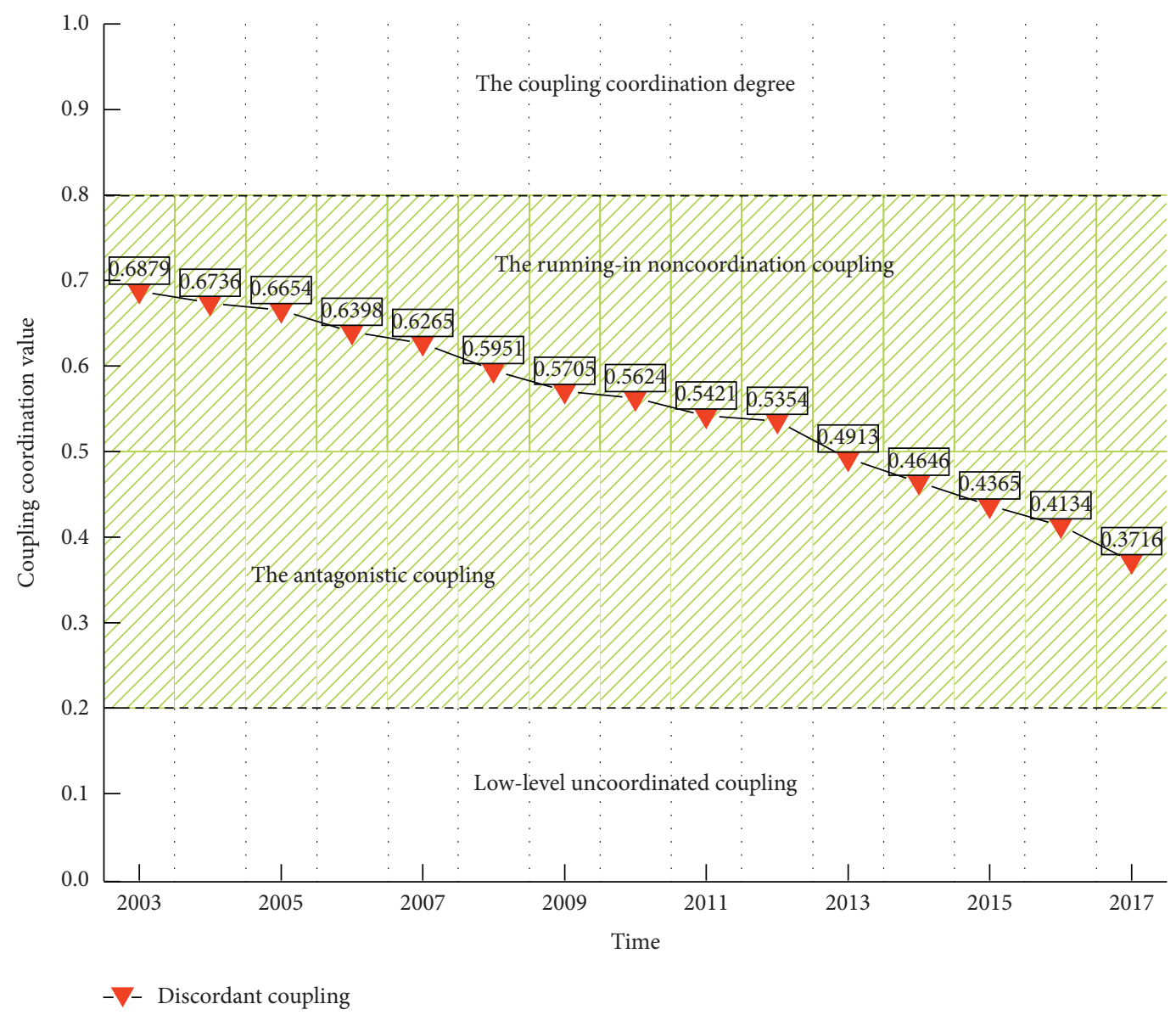

FIGURE 5: The noncoordination coupling evolution process of pro-poor tourism and eco-environment in Liupanshui city.

2003, tourism poverty alleviation investments were exceedingly few, and tourism poverty alleviation efficiency was really low, which was in line with the "southwest coal sea" in Liupanshui city that vigorously developed the coal industry and did not pay attention to the development of tourism. In 2009 , the tourism poverty alleviation development bureau of Liupanshui was established; the investment in tourism poverty alleviation increased significantly and the efficiency 
of poverty alleviation through tourism had been greatly improved. According to the weight of basic indicators in Table 1, the main indicators that affect the tourism poverty alleviation system are the incidence of poverty (0.1055), the number of people lifted out of poverty by tourism (0.1032), the number of poor people (0.0839), and the per capita net income of farmers $(0.0810)$, which means that the focus of the tourism poverty alleviation work is to increase the per capita net income of farmers, improve the number of people lifted out of poverty by tourism, and reduce the number and incidence of poverty.

4.2.2. Analyses of Ecological Environment Development Level in Liupanshui City. As can be seen from Table 3 and Figure 4 , during the research period, the development level of ecological environments and the poverty alleviation level of tourism show different stage characteristics. From 2003 to 2007, the level of ecological and environmental development increased rapidly, from 0.1726 to 0.3475 . From 2008 to 2012, it presented a slow rising stage, rising from the starting point of 0.4329 to 0.5409 . From 2013 to 2017, there was a comparatively fast rise, rising from 0.5985 to 0.7834 . From the perspective of the evolution process of each subsystem of the ecological environment, the ecological environment input and the ecological environment benefit showed a rising curve, rising from 0.0014 and 0.0003 in 2003 to 0.1939 and 0.4186 in 2017, respectively. The ecological environment pressure performs a process of decreasing first and then increasing later. Thereinto, from 2003 to 2012, the pressure of ecological environments decreased from 0.1709 to 0.1175 and then gradually increased to 0.1708 in 2017 . It can be seen that, from 2003 to 2012, with the increase of investment in ecological environments, ecological environmental benefits increased and ecological pressure gradually decreased. Since then, tourism poverty alleviation efforts have been increased, producing a certain pressure on ecological environments. It can be seen from the weight of basic indicators in Table 2 that the main indicators affecting the ecological environment system are vegetation coverage rate (0.1018), domestic sewage discharge rate $(0.1015)$, rate of days with good air quality (0.0852), and domestic sewage treatment rate (0.0849), indicating that, in the process of ecological environment construction, vegetation coverage rate should be increased, domestic sewage discharge should be reduced, and rate of days with good air quality and domestic sewage treatment rate should be increased.

\subsection{Discordant Coupling between Tourism Poverty Alleviation and Ecological Environments in Liupanshui City}

4.3.1. Analyses of the Discordant Coupling Degree between Tourism Poverty Alleviation and Ecological Environments. As can be seen from Table 3 and Figure 5, during the research period, the discordant coupling between tourism poverty alleviation and ecological environments in Liupanshui city unfolds a decreasing curve, from 0.6879 in 2003 to 0.3716 in 2017 , with a decrease of $85.12 \%$. It can be seen from the above four stages of tourism poverty alleviation and ecological environments that the discordant coupling between tourism poverty alleviation and ecological environments in Liupanshui city is in the second and third stage; namely, from 2003 to 2012, discordant coupling was antagonistic discordant coupling; from 2013 to 2017, it decreased to running-in uncoordinated coupling. This suggests that the uncoordinated development relationship between tourism poverty alleviation and ecological environments is significant, and its coupling presented a lower level of coupling stage, which means that the development of tourism poverty alleviation is at the expense of ecological environments. However, the coupling relationship between tourism poverty alleviation and ecological environments is gradually progressing towards a benign direction. It has been developed from running-in uncoordinated coupling to antagonistic uncoordinated coupling. However, there is still a lot of work to be done before it reaches the stage of lowlevel uncoordinated coupling.

4.3.2. Internal Mechanism Analyses of Discordant Coupling between Tourism Poverty Alleviation and Ecological Environments. As mentioned above, tourism poverty alleviation and ecological environments in Liupanshui city are in two stages of antagonistic uncoordinated coupling and running-in uncoordinated coupling, and the couplings are at relatively low level. The uncoordinated coupling mechanism leading to this phenomenon is as follows:

(1) Lack of rationality in evaluation of political achievements, social system, and environmental catalysis. Local governments have given priority to economic development, have given great attention to economic indicators in performance evaluation, and have established an evaluation system with GDP as a core achievement inspection to encourage development. This is a measure that assigns more importance to economic development than ecological environment construction. Local governments still consider GDP as an important indicator or even the only indicator. Led by industrial rigidity and development interests, local governments do not pay enough attention to the construction of ecological environments, and the construction of ecological environments often becomes a political slogan. At the same time, the term of taking office of local governments is 5 years, which affects the government's development strategy. Some strategies are not adopted by the government due to their long development time and slow effectiveness.

For example, ecological environment construction is not favored by local governments because of its slow effectiveness, long-term development, and lack of competitiveness. However, some heavy industries with quick returns, short time, and heavy pollution are given with the opportunity to build and bring rapid economic growth but lead to ecological contamination and destruction. In addition, in the process of tourism poverty alleviation, the 
government is eager for quick success and quick benefits. The government also plans to develop the tourism poverty alleviation resources in poor mountainous areas too quickly, explores resources unreasonably or even illegally, and occupies highyield farmland, lakes, and ecological wetlands in poor mountainous areas, which not only destroys the original scenery of poor mountainous areas but also worsens the ecological environment of them.

(2) Driven by local economic development. Liupanshui city is China's "coal capital in the south of the Yangtze river," which is rich in coal resources, so vigorously develops the coal mining industry, and relies on coal to develop thermal power industry and steel industry. These industries are typical high-energy-consumption and high-pollution industries, which increase the pressure on the ecological environment. At the same time, in order to achieve rapid economic growth, local government put forward the idea of utilizing resources as quickly as possible, regardless of ecological environment damage.

For example, the investment of Faer power plant in Shuicheng county is tens of billions Yuan; the procedures are not completed due to lack of adequate authorization. This blind start of production at the expense of the ecological environment incurs huge cost to economic development. On September 22, 2006, special inspection team of environmental protections of seven ministries under the state council inspected Liupanshui, and the municipal government believed that there were no polluting enterprises in Liupanshui. On January 10, 2007, the state environmental protection administration imposed regional restrictions on Liupanshui city in response to violations by high-pollution enterprises, including the Yemazhai power plant and Faer power plant, which were found to have serious violations.

The restrictions and rectification of these illegal polluters have undoubtedly played a good role in protecting the ecological environment of Liupanshui city. At present, along with the process of regional economic development and transformation, Liupanshui is vigorously developing the tourism industry. This development of tourism requires excellent ecological environments. Under the condition of the continuous increase of ecological environment investments, the ecological environment of Liupanshui is significantly ameliorated and the pressure of ecological environments is reduced. However, with the in-depth development of the tourism poverty alleviation work, the number of tourists is increased; especially in summer, the number of tourists coming to Liupanshui city, which is named "China's cool capital," for escaping the summer heat is augmented; the area once appears the phenomenon of "all hotel rooms are booked." Too many tourists have generated great pressure on ecological environments. Therefore, after 2013, ecological environmental pressure in Liupanshui city began to rise. Although the incongruent coupling relationship between tourism poverty alleviation and the ecological environment is developing in a good direction, there is still a long way to go, and the construction of ecological environments is a longterm process.

(3) There are natural environment constraints. Liupanshui city is the center of Karst Mountains in southwest China, and its karst landform is well developed. The distribution area of carbonate rocks is about $6263 \mathrm{~km}^{2}$, accounting for $63 \%$ of the total land area. Thereinto, the area of rocky desertification is $2575 \mathrm{~km}^{2}$, accounting for about $26 \%$ of the land area, which is one of the most serious areas of rocky desertification in karst mountainous areas in southwest China. The fragile ecological environment in karst mountainous area is vulnerable to damage and difficult to repair after disfiguration. Due to local financial pressure, the construction and protection of ecological environments are neglected intentionally or unintentionally. At the same time, due to people's insufficient understanding of the vulnerability of the ecological environment in Karst Mountains, the ecological environment in mountainous areas is damaged from time to time in the process of economic development. For example, for building a reservoir to gather water, the related departments unexpectedly rechanneled the river in Liuche valley of Liupanshui city to divert the water source to the location where the reservoir is built. This river rechanneled project has led to the fact that there is no water source in the Liuche valley any more, forming a dry valley, which badly affects the original landform and vegetation of the canyon and damages the ecological environment.

However, in recent years, with the deepening of the concept of "green waters and mountains are mountains of gold and silver," people gradually realize the importance of ecological environments. In the process of tourism poverty alleviation, people gradually recognize the importance of ecological environment protections, consciously build ecological environments, and increase investments in ecological environment protections and governance in order to enhance the noncoordinated coupling between ecological environments and tourism poverty alleviation development inch by inch. Due to insufficient investments, there is still a long way to govern and build the ecological environment.

\subsection{Countermeasures and Suggestions on Tourism Poverty Alleviation and Ecological Environment Protections in Liupanshui City}

4.4.1. Tourism Poverty Alleviation and Ecological Environment Construction Are Carried out Simultaneously. In poor mountainous areas, social and economic development is 
backward, and construction funds are insufficient. In the early stage of tourism poverty alleviation development, the funds are mostly used for the construction of tourism poverty alleviation and development projects, while limited funds are used for ecological and environmental protection. In 2003, the environmental investment index was only 0.72 , the domestic sewage discharge rate was $48.51 \%$, and the domestic garbage discharge rate was $74.00 \%$. Even now, there is no guarantee that the discharge of domestic sewage and domestic garbage reaches 100 percent, and the contamination is even more serious during the peak period of tourism. Therefore, in the process of increasing the investment in tourism poverty alleviation and promoting the development of tourism, the investment in ecological environment construction should be increased, ensuring that all kinds of domestic pollution discharge reach $100 \%$ to avoid the destruction of ecological environments and ensuring synchronous and coordinated development of tourism poverty alleviation and ecological environments.

4.4.2. Improve and Enhance the Ecological and Environmental Protection System to Avoid Blind Planning and Disordered Development of Tourism Resources. In the process of tourism poverty alleviation, the blind planning and disordered development of tourism resources should be avoided. In order to attract tourists and maximize tourism revenue, it is necessary to improve several aspects such as unreasonable exploration of land resources, even illegal development, disordered distribution of construction facilities, river rechannel, and ecological damage in the process of tourism resource development. For example, in some core scenic areas of primitive ecological villages, there is deforestation and large hotels have been built, resulting in the reduction of natural forest land and regional forest cover and the destruction of the original forms of small bridges, rivers, and houses in villages. Therefore, the ecological environment protection system should be enhanced to avoid the disordered development of tourism resources as well as blind planning. By these measurements, original village ecological environment can be protected.

\subsubsection{Set a Reasonable Tourism Environment Capacity to} Prevent the Overload Operation of the Scenic Spot Environment. In order to ensure coordinated development of tourism poverty alleviation and ecological environments, it is necessary to reasonably calculate and set the tourism environmental capacity of the scenic spot. It should be done according to the size of recreation space provided by each tourist at poverty alleviation scenic spot and the length of sightseeing time. This is necessary to avoid the overloaded operation where tourist flow exceeds the scenic spot environmental capacity, which causes damage to the ecological environment.

\section{Conclusions and Discussion}

5.1. Main Conclusions. In this study, the variation coefficient method is used to determine the weight of each evaluation index, and the uncoordinated coupling model between tourism poverty alleviation and ecological environments is established. The noncoordinated coupling relationship and evolution between tourism poverty alleviation and ecological environments in Liupanshui city from 2003 to 2017 are analyzed, and the following conclusions are obtained:

(1) According to the respective evolution of tourism poverty alleviation and ecological environments, during the research period, the development level of tourism poverty alleviation in Liupanshui shows an increasing curve, from 0.2198 in 2003 to 0.7963 in 2017 , with an increase rate of $262.28 \%$. The development level of ecological environments and tourism poverty alleviation performs different stage characteristics. From 2003 to 2007, the ecological environment development level showed a rapidly rising trend, rising from the starting point of 0.1726 to 0.3475 . From 2008 to 2012 , it showed a slow rising stage, from the starting point of 0.4329 to 0.5409 . From 2013 to 2017, a relatively fast rise unfolded, from 0.5985 to 0.7834 .

(2) From the perspective of the discordance coupling between tourism poverty alleviation and ecological environments, the discordance coupling between tourism poverty alleviation and ecological environments in Liupanshui city presents a decreasing curve, from 0.6879 in 2003 to 0.3716 in 2017 , with a decrease rate of $85.12 \%$. Thereinto, from 2003 to 2012 , incongruent coupling was antagonistic incongruent coupling. From 2013 to 2017, it decreased to running-in uncoordinated coupling. This suggests that the uncoordinated development relationship between tourism poverty alleviation and ecological environments is significant, and its coupling is manifested as a lower-level coupling stage, which means that the development of tourism poverty alleviation is at the expense of ecological environments. However, the coupling relationship between tourism poverty alleviation and ecological environments is gradually progressing towards a benign direction, which has developed from running-in uncoordinated coupling to antagonistic uncoordinated coupling.

\subsection{Discussion}

(1) In this paper, the identification of noncoordination coupling relationship between tourism poverty alleviation and the ecological environment is described and defined. The study also builds the theorem of noncoordination between tourism poverty alleviation and the ecological environment. It is a bridge constructed on the basis of perspectives of reverse thinking and problem diagnosis from uncoordinated pathology to coordinated development. On the one hand, it expands the new perspective of the research on tourism poverty alleviation and ecological environments, which is a beneficial supplement to the 
current relative lack of scientific evaluation, and also improves the harmonious development of tourism poverty alleviation and ecological environments. On the other hand, it provides a comparison and reference for the scientific identification of the coordinated and noncoordinated state of China's current tourism poverty alleviation and ecological environment development and consequently provides a theoretical basis for revealing its causes and proposing targeted optimization and regulation policies.

(2) Tourism poverty alleviation and ecological environments are a pair of coupling bodies of dissipation structure. In the process of tourism poverty alleviation development, each subsystem of tourism poverty alleviation often needs to exchange and transform materials and energy with each subsystem of ecological environments, which contains various coordinated and uncoordinated coupling states. Therefore, on the basis of reverse thinking and problem diagnosis, coupling developing from inharmonious pathology to harmonious benign development is of great significance to the sustainable development of local economy and society. The issue of inharmonious coupling between tourism poverty alleviation and ecological environments is necessary to promote the tourism poverty alleviation and ecological environment.

(3) The noncoordinated coupling and evolution of tourism poverty alleviation and ecological environments play an important role in the study of the dynamic change process and internal formation mechanism of the system. However, relevant information and statistical data are difficult to obtain; therefore research period of 15 years from 2003 to 2017 is studied. It requires a long sequence of time for analysis in order to be more consistent with actual dynamic changes. In the future, scenic spots with more data and information will be selected for research.

(4) This paper studies the uncoordinated coupling relationship between tourism poverty alleviation and ecological environments in Liupanshui city from 2003 to 2017 and obtains some conclusions for reference. However, it neither conducts comparative studies on specific scenic spots such as A-level scenic spots and scenic attractions nor discusses the internal links of the noncoordination and coordination relationship between tourism poverty alleviation and ecological environments. In the future, in-depth analyses will be conducted on these aspects.

\section{Data Availability}

The data used to support the findings of this study are available from the corresponding author upon request (e-mail: Qinqu2008@126.com).

\section{Conflicts of Interest}

The authors declare no conflicts of interest.

\section{Authors' Contributions}

Qu Qin designed the study and wrote the manuscript. The data from yearbooks and professional websites are retrieved by Zeli $\mathrm{Hu}$, Anle Liu, and Yan Huang. Fengtai Zhang provided important ideas and suggestions.

\section{Acknowledgments}

This work was partially supported by the National Social Science Foundation Program (19BJY213).

\section{References}

[1] R. Scheyvens, "Exploring the tourism-poverty nexus," Current Issues in Tourism, vol. 10, no. 2-3, pp. 231-254, 2007.

[2] L. H. Xu, "Effects of rural pro-poor tourism on farming households' income: a study based on the PSM-DID method," Resources Science, vol. 41, no. 5, pp. 955-966, 2019.

[3] D. Schilcher, "Growth versus equity: the continuum of propoor tourism and neoliberal governance," Current Issues in Tourism, vol. 10, no. 2-3, pp. 166-193, 2007.

[4] B. Zeng and C. Ryan, "Assisting the poor in China through tourism development: a review of research," Tourism Management, vol. 33, no. 2, pp. 239-248, 2012.

[5] T. Sofield, J. Bauer, T. De Lacy et al., Sustainable TourismEliminating Poverty (ST-EP): An Overview, pp. 1-10, CRC for Sustainable Tourism Pty Ltd, Gold Coast, Australia, 2004.

[6] H. Chen, Q. Xu, and R. Q. Guo, "Temporal and spatial evolution of the coupling coordinated development between tourism resources development and ecological environment in China," Economic Geography, vol. 36, no. 6, pp. 233-240, 2019.

[7] T. Sofield, J. Bauer, T. De Lacy et al., Sustainable TourismEliminat-Ing Poverty (ST-EP): An Overview[R/OL]. [2014-0918], Cooperative Research Center for Sustainable Tourism, Gold Coast, Australian, 2004.

[8] S. W. Yang, "Review of overseas research on pro-poor tourism," Human Geography, vol. 30, no. 1, pp. 26-32, 2015.

[9] S. Pulvirenti, P. Pavone, R. A. Carbonaro, and R. M. S. Costa, "Taxonomic study of the plants to be found in the onlyherbariumof Paolo Boccone (1633-1704) at present existing in Italy," Plant Biosystems-An International Journal Dealing with All Aspects of Plant Biology, vol. 151, no. 4, pp. 745-759, 2017.

[10] S. Pulvirenti, P. Pavone, R. A. Carbonaro, and R. M. S. Costa, "The controversial biography of paolo boccone (1633-1704) and his "grand tour" from the mediterranean to northern europe," Plant Biosystems-An International Journal Dealing with All Aspects of Plant Biology, vol. 151, no. 3, pp. 377-380, 2017.

[11] M. S. Lin, J. H. Lin, K. Y. Wang et al., "Evaluation of sustainable tourism for eliminating poverty in key villages based on risk matrix method: a case study of Fujian Province," Geography Resource, vol. 37, no. 12, pp. 2517-2527, 2018.

[12] P. J. Sun, C. L. Xiu, and F. Lv, "Basic theory and empirical analysis of non-coordination identification of urban spatial expansion," Advances in Earth Science, vol. 30, no. 2, pp. 247-258, 2015.

[13] M. Melnykovych, M. Nijnik, I. Soloviy, A. Nijnik, S. Sarkki, and Y. Bihun, "Social-ecological innovation in remote mountain areas: adaptive responses of forest-dependent communities to the challenges of a changing world," Science of the Total Environment, vol. 613-614, pp. 894-906, 2018. 
[14] S. Aryal, G. Cockfield, and T. N. Maraseni, "Globalisation and traditional social-ecological systems: understanding impacts of tourism and labour migration to the transhumance systems in the Himalayas," Environmental Development, vol. 25, pp. 73-84, 2018.

[15] R. K. Maikhuri, A. Nautiyal, N. K. Jha et al., "Socio-ecological vulnerability: assessment and coping strategy to environmental disaster in Kedarnath valley, Uttarakhand, Indian Himalayan Region," International Journal of Disaster Risk Reduction, vol. 25, pp. 111-124, 2017.

[16] Q. Wang, M. H. Yin, X. Z. Yang et al., "Spatio-temporal evolution and impact mechanism of socio-ecological system vulnerability in poor mountainous tourist distinations: taking Dabie Mountain area as example," Acta Geography Sinica, vol. 74, no. 8, pp. 1663-1679, 2019.

[17] W. W. I. Alvarez and S. Martin, "Sustainability analysis: Viability concepts to consider transient and a symptotical dynamics in so-cio-ecological tourism-based systems," Ecological Modelling, vol. 251, pp. 103-113, 2013.

[18] T. M. Patterson, V. Niccolucci, and N. Marchettini, "Adaptive environmental management of tourism in the Province of Siena, Italy using the ecological footprint," Journal of Environmental Management, vol. 86, pp. 407-418, 2008.

[19] Z. Tang, "An integrated approach to evaluating the coupling coordination between tourism and the environment," Tourism Management, vol. 46, no. 46, pp. 11-19, 2015.

[20] Q. Wang, Z. Mao, L. Xian, and Z. Liang, "A study on the coupling coordination between tourism and the low-carbon city," Asia Pacific Journal of Tourism Research, vol. 24, no. 6, pp. 550-562, 2019.

[21] Z. F. Wang, F. F. Huo, and S. Xu, "Coupled development and regional differences between tourism industry and tourism environments in Hunan, Hubei, Chongqing and Guizhou," Economic Geography, vol. 38, no. 8, pp. 204-213, 2018.

[22] W. Q. Gao and Y. X. Wang, "Research on coupling coordinative degree between tourism industry and ecological environments of Changshan islands," Areal Research and Development, vol. 36, no. 3, pp. 103-107, 2017.

[23] P. Yi, S. M. Fang, and C. Y. Ma, "Decoupling evaluation between tourism economic growth and eco-environment al pressure of Songshan global geopark," Journal of Natural Resources, vol. 29, no. 8, pp. 1282-1296, 2014.

[24] S. T. Geng and Y. J. Xie, "Research on coupling relation between tourism economy and ecological environments of China's sub-provincial cities," Urban Development Studies, vol. 20, no. 1, pp. 91-97, 2013.

[25] Y. Fan, C. Fang, and Q. Zhang, "Coupling coordinated development between social economy and ecological environment in Chinese provincial capital cities-assessment and policy implications," Journal of Cleaner Production, vol. 229, no. 229, pp. 289-298, 2019.

[26] Y. Ma, L. X. Li, and J. Ren, "Coordination development research among the tourism economy- traffic condition-ecological environments in Shengnongjia forest district," Economic Geography, vol. 37, no. 10, pp. 215-220, 2017.

[27] A. Duro, V. Piccione, M. A. Ragusa, and V. Veneziano, "New enviromentally sensitive patch index-ESPI-for MEDALUS protocol," in AIP Conference Proceedings, vol. 1637, pp. 305-312, Surakarta, Indonesia, February 2014.

[28] A. Cuspilici, P. Monforte, and M. A. Ragusa, "Study of Saharan dust influence on PM 10 measures in Sicily from 2013 to 2015," Ecological Indicators, vol. 76, pp. 297-303, 2017.

[29] Q. Qin, S. P. Zhu, and W. Dai, "A dynamic approach to the assessment of urban ecosystem health in Liupanshui City,"
Environmental Science \& Technology, vol. 37, pp. 185-191, 2014.

[30] People's Publishing House, "Communist party of China Liupanshui municipal committee, Liupanshui city people's government," Liupanshui "three changes" Reform: Exploration on the New Road of Rural Reform in China, People's Publishing House, Beijing, China, 2016.

[31] J. D. Wang and J. Wang, "The practical background, core meaning and extension value of the "three changes," Reform, vol. 30 , no. 8 , pp. $5-15,2017$.

[32] P. J. Sun, "Identification of non-coordination between urbanization and ecological environments in Jiangsu province during 1994-2011," Resources and Environments in the Yangtze Basin, vol. 23, no. 8, pp. 1051-1056, 2014.

[33] P. F. Shi, X. M. Li, and Y. B. Xiong, "Coupling measurement and prospect forecast of regional "beautiful China" construction and tourism industry development: a case study of 11 provinces along the Yangtze river economic belt," China Soft Science, vol. 33, no. 2, pp. 86-102, 2018.

[34] Q. An, Z. P. Yang, X. L. Xu et al., "Spatial correlation of poverty and tourism resources in three prefactures in South Xinjiang," Progress in Geography, vol. 35, no. 4, pp. 515-525, 2016.

[35] Y. H. Qin, D. X. Liu, H. Qin et al., "Coupling of pro- poor tourism and ecological protection in the contiguous destitute areas: a case study of Xiannvshan town in Wulong county," Journal of Southwest University (Social Sciences Edition), vol. 42, no. 3, pp. 69-77, 2016.

[36] M. S. Lin, J. H. Lin, Y. Chen et al., "Ecological vulnerability assessment of key villages of tourism poverty alleviation in Fujian Province," Acta Ecologica Sinica, vol. 38, no. 19, pp. 7093-7101, 2018.

[37] M. D. Zhang and D. Y. Mo, "Coupling coordination degree of urban land use benefit and urbanization," Resources Science, vol. 36, no. 1, pp. 8-16, 2014.

[38] F. T. Zhang, W. C. Su, and J. X. Zhou, "Assessment of urban ecological security based on entropy- weighted gray correlation analysis," Chinese Journal of Ecology, vol. 7, pp. 1249$1254,2008$.

[39] P. J. Sun, S. B. Ding, and C. L. Xiu, "Dynamic evolution research on non-conformity of urban construction land input in China," Scientia Geographica Sinca, vol. 32, no. 9, pp. 1048-1053, 2012.

[40] P. J. Sun, S. B. Ding, C. L. Xiu et al., "Population-EconomySpace urbanization of northeast China," Scientia Geographica Sinca, vol. 32, no. 4, pp. 450-457, 2012.

[41] M. Reng, Y. Chen, and J. L. Reng, "Identification of non-coordination between urbanization and ecological environment in Shandong province," World Regional Studies, vol. 25, no. 5, pp. 58-68, 2016.

[42] Y. Geng, M. Maimaituerxun, and H. Zhang, "Coupling coordination of water governance and tourism: measurement and prediction," Discrete Dynamics in Nature and Society, vol. 2020, Article ID 3683918, 13 pages, 2020. 